\title{
Projecting Safety Measures in Fireworks Factories in Sivakasi using Fuzzy based Approach
}

\author{
P. Tamizhchelvi \\ Department of Computer Science, \\ Ayya Nadar Janaki \\ Ammal College,Sivakasi, \\ TamilNadu, \\ India
}

\begin{abstract}
Fuzzy logic is an approach to computing based on "degrees of truth" rather than the usual "true or false" (1 or 0$)$ boolean logic on which the modern computer is based. Fuzzy logic can handle problems with imprecise and incomplete data, and it can model nonlinear functions of arbitrary complexity. A fuzzy set is any set that allows its members to have different grades of membership in the interval $[0,1]$. Sivakasi is the major hub for the entire country's fireworks. 50-75 workers die every year in fire accidents in this industry and many here have chronic respiratory problems. To help these people to work in a safety environment is the objective of this project. As the situation of accidents has lot of ambiguity, fuzzy logic was selected. Various parameters that lead to accidents were analysed and Fuzzy logic, one of the soft computing techniques is applied to find out the parameters where safety needs to be tightened were obtained.
\end{abstract}

\section{Keywords}

Fuzzy logic, Fuzzy set, membership functions, crisp set,fuzzification, defuzzification.

\section{INTRODUCTION}

[1]Fuzzy logic is an approach to computing based on "degrees of truth" rather than the usual "true or false" ( 1 or 0$)$ boolean logic on which the modern computer is based. It is a form of many-valued logic. It deals with reasoning that is approximate rather than fixed and exact. Compared with traditional binary sets (where variables may take on true or false values) fuzzy logic variables may have a truth value that ranges in values between 0 and 1 . Fuzzy logic has been extended to handle the concept of partial truth where the truth value may range between completely true and completely false. Fuzzy logic can handle problems with imprecise and incomplete data, and it can model nonlinear functions of arbitrary complexity. This logic incorporates a simple, rule-based IF X AND Y THEN Z approach to solve a control problem rather than attempting to model a system mathematically.

\section{FUZZY SET THEORY}

[2]A fuzzy set is any set that allows its members to have different grades of membership in the interval [0,1]. It provides a strict mathematical framework in which vague phenomena can be precisely and rigorously studied. It can also be considered as a modelling language well suited to the situations in which fuzzy relations, criteria and phenomena exist.

A fuzzy set is defined as follows.
If $\mathrm{X}$ is a universe of Discourse and $\mathrm{x}$ is particular element of $X$ then a fuzzy set A defined on $X$ may be written as a collection of ordered pairs.

$$
A=\{(\mathrm{x} \cdot \mu \tilde{\mathrm{A}}(\mathrm{x})), x \in X\}
$$

where each pair $((x, \mu A(x)))$ is called a singleton.

\section{MEMBERSHIP FUNCTIONS}

The [3]membership function is a graphical representation of the magnitude of participation of each input. The $x$ axis represents the universe of discourse, whereas the $y$ axis represents the degrees of membership in the $[0,1]$ interval. It associates a weight with each of the input that is processed, define functional overlap between inputs and ultimately determines output response. Simple functions are used to build membership functions. Because we are defining fuzzy concepts, using more complex functions does not add more precision.

\subsection{Types}

There are several types of functions available. Some of them are:

- Triangular membership functions

- Bell membership functions

- Trapezoidal membership functions

\subsubsection{Triangular membership functions}

The simplest membership function is the triangular membership function. It's nothing more than a collection of three points forming a triangle.

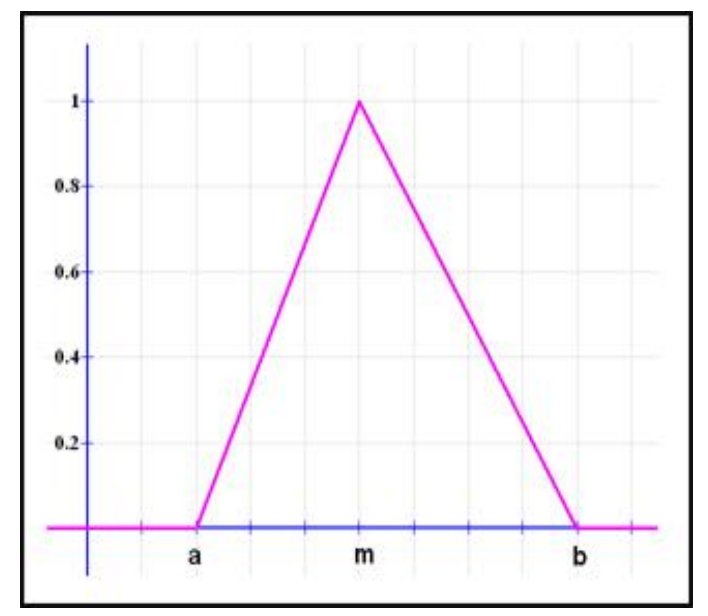




$$
\mu_{A}(x)= \begin{cases}0, & x \leq a \\ \frac{x-a}{m-a}, & a<x \leq m \\ \frac{b-x}{b-m}, & m<x<b \\ 0, & m \geq b\end{cases}
$$

\subsubsection{Trapezoidal membership functions}

The trapezoidal membership function has a flat top and it is just a truncated triangle curve. These straight line membership functions have the advantage of simplicity.

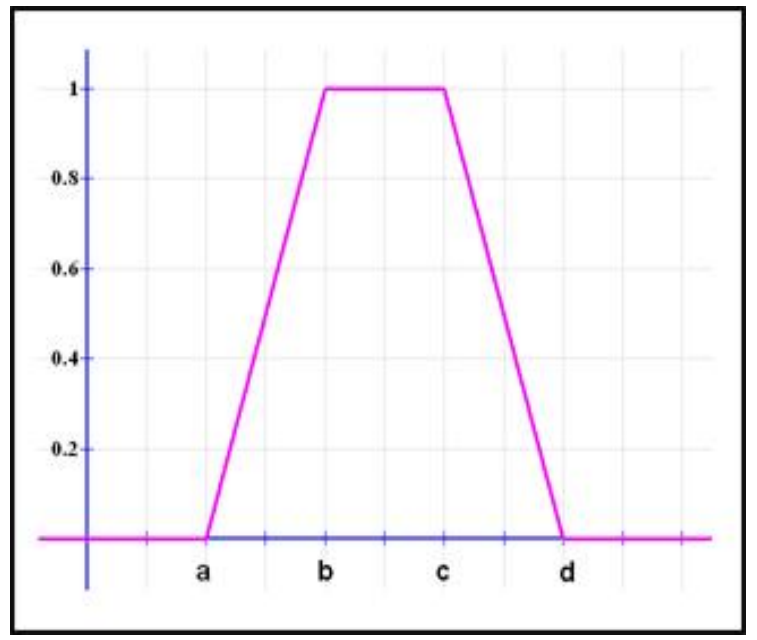

$$
\mu_{A}(x)= \begin{cases}0, & (x<a) \text { or }(x>d) \\ \frac{x-a}{b-a}, & a \leq x \leq b \\ 1, & b \leq x \leq c \\ \frac{d-x}{d-c}, & c \leq x \leq d\end{cases}
$$

\subsubsection{Bell membership functions}

The bell membership function is specified by three parameters.Because of their smoothness and concise notation, bell membership functions are popular methods for specifying fuzzy sets. These curves have the advantage of being smooth and nonzero at all points.

\section{LINGUISTC VARIABLES}

[4]A variable whose values are not numbers but words or sentences are called linguistic variables. Small, Medium, Large are examples of linguistic variables. The states of each linguistic variable are expressed by linguistic terms of a base variable. The values of the base variables are within specific range of real numbers. In a linguistic variable, linguistic terms representing approximate values of a base variable are captured by appropriate fuzzy numbers.

\section{APPLYING FUZZY LOGIC}

Any problem to be solved in fuzzy logic should undergo the following steps

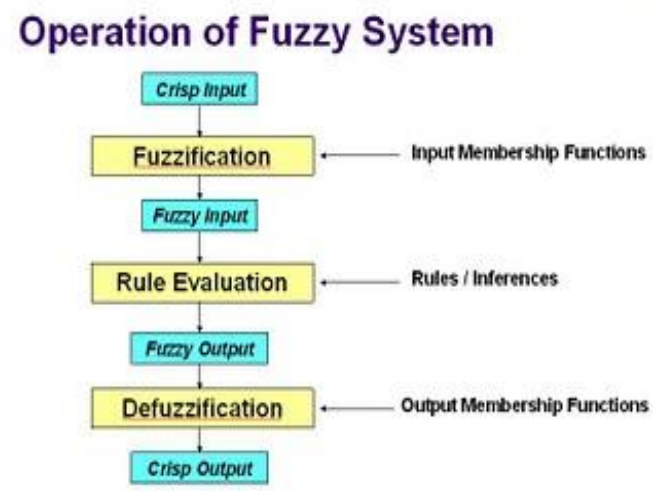

\subsection{Collection of Crisp Input}

A conventional set, wherein the degree of membership of any object in the set is either 0 or 1. Fuzzy logic is a mathematical or computer program that attempts to approximate the ambiguity inherent to human reasoning. Here, the parameters used to predict the safety level of fireworks factories are collected.

\subsection{Fuzzification}

The [5]fuzzification comprises the process of transforming crisp values into grades of membership for linguistic terms of fuzzy sets. The membership function is used to associate a grade to each linguistic term.

\subsection{Rule Base Engine}

A rule based system consists of if-then rules, a bunch of facts, and an interpreter controlling the application of the rules, given the facts. These if-then rule statements are used to formulate the conditional statements that comprise the complete knowledge base. A single if-then assumes the form 'if $x$ is $A$ then $y$ is $B$ ' and the if-part of the rule ' $x$ is $A$ ' is called the antecedent or premise, while the then-part of the rule ' $\mathrm{y}$ is $\mathrm{B}$ ' is called the consequent or conclusion.

There are two broad kinds of inference engines used in rulebased systems: forward chaining and backward chaining system. In a forward chaining system, the initial facts are processed first and keep using the rules to draw new conclusions given those facts. In a backward chaining system, the hypothesis (or solution/goal) we are trying to reach is processed first, and keep looking for rules that would allow concluding that hypothesis. As the processing progresses, new sub goals are also set for validation. Forward chaining systems are primarily data-driven, while backward chaining systems are goal-driven.

\subsection{Defuzzification}

[6]Defuzzification is a reverse process of fuzzification. Defuzzification is used to obtain a crisp output. Since technical processes require crisp control actions, a procedure generates crisp value out of one or more fuzzy output. The crisp value to be chosen should generally be from one of the following methods.

- Centroid Method

- Centre of Sums Method

- Mean of Maxima 


\subsubsection{Centroid method}

The most popular one is the centroid technique. It finds the point where a vertical line would slice the aggregate set into two equal masses. Centroid defuzzification method finds a point representing the centre of gravity of the fuzzy set $\mathrm{A}$, on the interval, ab. A reasonable estimate can be obtained by calculating it over a sample of points.

\subsubsection{Center of Sums}

In the center of sums $(\mathrm{CoS})$ defuzzification method, the fuzzy logic controller first calculates the geometric center of area for each membership function, as the following figure illustrates:

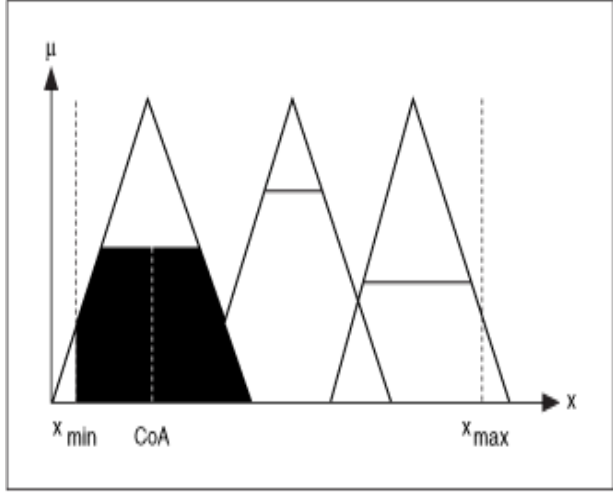

\section{Center of Sums}

The fuzzy logic controller then uses the following equation to calculate a wighted average of the geometric center of area for all membership functions.

$$
x_{\text {final }}=\frac{\operatorname{CoA}_{1} \text { area }_{1}+\text { CoA }_{2} \text { area }_{2}+\ldots+\text { CoA }_{n} \text { area }_{n}}{\text { area }_{1}+\text { area }_{2}+\ldots+\text { area }_{n}}
$$

Where CoAn is the geometric center of are of the scaled membership function $\mathrm{n}$ and area is the area of the scaled membership function $\mathrm{n}$.

\subsubsection{Mean of Maximum}

In the mean of maximum (MoM) defuzzification method, the fuzzy logic controller first identifies the scaled membership function with the greatest degree of membership.

The fuzzy logic controller then determines the typical numerical value for that membership function. The typical numerical value is the mean of the numerical values corresponding to the degree of membership at which the membership function was scaled. The following figure illustrates the MoM defuzzification method:

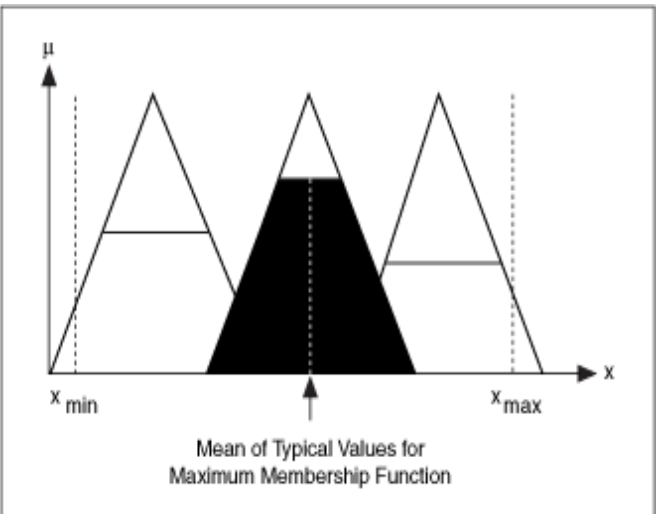

Mean of Maximum

\section{PROBLEM DESCRIPTION}

$[7,8,9]$ Sivakasi is the major hub for the entire country's fireworks. But, frequent accidents have blotted its speciality and 50-75 workers die every year in fire accidents in this industry and still many carry painful scars - a broken leg or skull or a hand burnt by explosives and many here complain of chronic respiratory problems. To help these people to work in a safety environment is the objective of this project. As the situation of accidents has lot of ambiguity, fuzzy logic was selected. Various parameters that lead to accidents were analysed and FuzzyLogic, one of the soft computing techniques is applied to find out the parameters where safety needs to be tightened were obtained.

\subsection{Implementation}

This work was tried in [10]xfuzzy 3.0 open source software.

\subsection{Modules}

Module Description

\section{Data collection \\ Fuzzification \\ Rule Base Design \\ Defuzzification}

\subsubsection{Data collection}

Many factories in and around Sivakasi have been visited and also surfed the net for more details. [11]Ministry of commerce and Industry Act, Govt of India published rules \& regulation for the safety of the fireworks.

(1) Not more than four persons shall be allowed at any one time in any one building or tent in which the explosive is being manufactured and only persons actually employed in manufacturing or superintending manufacture shall be allowed inside the place of manufacture.

(2) All explosives in the premises shall be manufactured and kept in a building substantially constructed of brick, stone or concrete or in a securely constructed fireproof safe and shall be separated from any dwelling house, highway, street, public thoroughfare building or public place or another licensed premises by the safe distances as mentioned in the license and its enclosures.

(3) No explosive other than specified in the [12]license in form LE-1 shall be kept in the premises

(4) The fireworks/gunpowder shall be manufactured in single storied building and all doors of the building shall open outwards.

(5) The interior of every building and receptacle used for explosives and the shelves and fittings therein shall be so constructed or so lined and covered as to prevent the exposure of any iron or steel, or the detaching of any grit, iron steel or similar substance, in such manner as to come into contact with the explosives. Such interior, shelves and fittings shall, so far as reasonably practicable, be kept free from grit and otherwise clean.

(6) The building or receptacle in which explosive is kept shall be used only for the keeping of such explosive and for no other purpose whatsoever.

(7) Fireworks shall be kept in separate receptacles or shall be so separated as to prevent explosion or fire communicating from one to the other. 
(8) All explosives exceeding 0.5 kilograme in amount shall be packed and marked in accordance with the rules.

(9) The explosive shall be manufactured in rooms of lightly constructed one-storied building kept and used only for the purpose of such manufacture and separated from the storage place by a distance of 45 metres and separated from any dwelling house, other building, another licensed premises, highway, street, public thoroughfare or public place by a distance of 45 meters.

(10) The ingredients for the manufacture of gunpowder shall be kept in separate stores distinct from each other and separated by a distance of at least 45 meters from the place where gunpowder/fireworks is manufactured or stored.

\subsubsection{Fuzzification}

\section{Declare crisp input and apply fuzzification}

It was decided to use 8 base variables based on the above rules stipulated, which would mainly affect the safety of the fireworks. According to their importance for the safety of the factories, membership functions have been assigned.
Parameters

Membership values

- $\quad$ Thickness of walks

0.87

- No of doors

0.98

- No of ventilators

0.91

- Experience of employees

0.95

- Sensitivity of chemicals

0.97

- Safety level distance

0.90

- No of fire extinguishers

0.90

- Quality of Ingredients

0.85
[5]Fuzzification of parameters

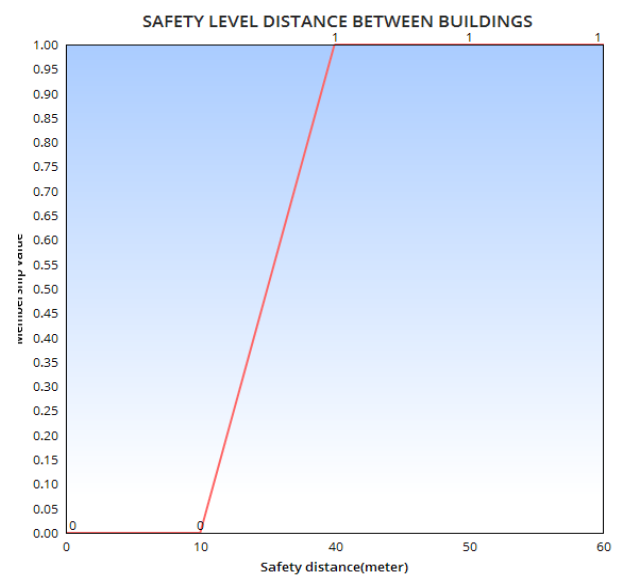

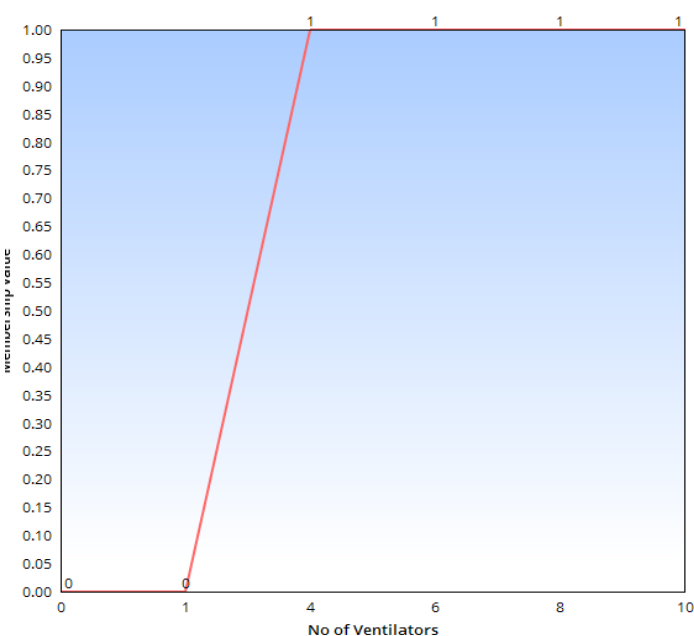

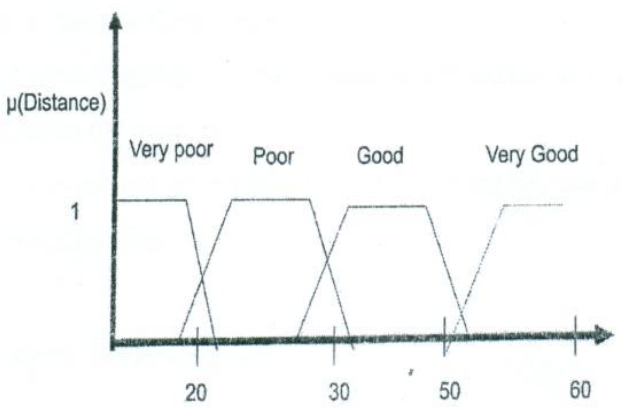

Distance (meters)

\section{Membership function of Distance}

Data for these 8 attributes were collected from the factories and other resources \& consulting the supervisors and boardman of the factories for estimating the attributes and assigned the Linguistic variables like Very good, Good, Poor, Very Poor to each attribute

\subsubsection{Rule base design}

Here, for a factory, the values of the attributes selected were compared and grouped their performances in the ranges of safe, Danger, Better etc.

\section{If-then rules for Chemical Composition}

If chemical Composition is greater than or equal to 0.87 then

Very Good in Chemical Composition

Else if chemical composition is greater than or equal to 0.75 and less than or equal to 0.86 then

\section{Good in Chemical Composition}

Else if Chemical composition is greater than or equal to 0.50 and less than or equal to 0.74 then

Bad Chemical Composition

Else 
Very poor Chemical Composition

\section{If-then rules for safety distance}

If safety distance between buildings is greater than or equal to 0.87 then [above 50 meters]

$$
\text { Very good in safety }
$$

Else safety distance is greater than or equal to 0.75 and less than or equal to 0.86 then [40-50]

\section{Good in safety}

Else is safety distance is greater than or equal to 0.50 and less than or equal to 0.74 then [35-40 meters]

Bad in safety

Else

Very bad in safety

\section{If-then rules for no of ventilators}

If No of ventilators in buildings is greater than or equal to 0.87 then [above 6]

Very good in safety

Else No of ventilators in buildings is greater than or equal to 0.75 and less than or equal to 0.86 then [4-6]

\section{Good in safety}

Else No of ventilators in buildings is greater than or equal to 0.50 and less than or equal to 0.74 then [2-4]

\section{Bad in safety}

\section{If-then rules for no of doors(no of doors)}

If No of doors in the buildings greater than or equal to 0.87 then [above 3]

$$
\text { Very good in safety }
$$

Else If No of doors in the buildings is greater than or equal to 0.75 and less than or equal to 0.86 then [2-3]

\section{Good in safety}

Else If No of doors in the buildings is greater than or equal to 0.40 and less than or equal to 0.74 then [1-2]

$$
\text { Bad in safety }
$$

Else

$$
\text { Very bad in safety }
$$

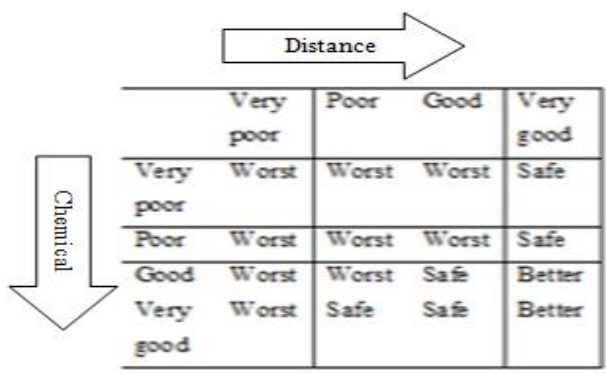

Sample Rule base Decision Table for Distance and Chemical composition

Using if-then rules, the safety levels of fireworks were grouped under Worst, Safe, Better categories. On projecting the safety measures of fireworks in the rule base process, it may be classified into two or more categories. This is called overlapping.

\subsubsection{Defuzzification}

Fuzzy logic is a rule-based system written in the form of horn clauses (i.e., if-then rules.) These rules are stored in the knowledge base of the system. The input to the fuzzy system is a scalar value that is fuzzified. The set of rules is applied to the fuzzified input. The output of each rule is fuzzy. These fuzzy outputs need to be converted into a scalar output quantity so that the nature of the action to be performed can be determined by the system. The process of converting the fuzzy output to crisp output is called [13]defuzzification. Before an output is defuzzified, all the fuzzy outputs of the system are aggregated with a union operator. The union is the max of the set of given membership functions and can be expressed as $\quad \mu \mathrm{A}=\mathrm{U}_{\mathrm{i}}\left(\mu_{\mathrm{i}}(\mathrm{x})\right)$

The Defuzzification is needed only if the overlapping occurs in rule base process, The crisp output must be calculated using any one of the three methods. Here, Mean of Maxima method. is selected.

In the Mean of Maximum (MoM) defuzzification method, the fuzzy logic controller first identifies the scaled membership function with the greatest degree of membership. The fuzzy logic controller then determines the typical numerical value for the membership function. The typical numerical value is the mean of the numerical values corresponding to the degree of membership at which the membership function was scaled.

Fuzzification result is converted into the following set = $\{\mathrm{W}, \mathrm{S}, \mathrm{B}\} \rightarrow$ \{Worst, Safe, Better $\}$

A factory ' $\mathrm{X}$ ' produces the following fuzzified output

(i). Chemical Composition and Distance produce the result : Safe $\rightarrow\{S\}$

ii) No of labours and No of Doors produce the result : Better $\rightarrow\{\mathrm{B}\}$

Decision $=\{0.5,0.4\}$

Now, safety of the factory comes under the decision D = \{Safe, Better\}, so the output must be fuzzified. Fuzzy set with the largest membership value is selected. Final Decision for the particular factory safety level is $=$ SAFE.

\section{CONCLUSION}

It is quite unfortunate to state that indian firecracker industry is noted for its high accident rate. A report of the Petroleum and Explosives Safety Organisation says that an average of 25 workers die every year due to mishandling of chemicals, violating the safety norms, employing inexperienced child worker and lack of medical facilities. This paper addressed the issues by taking few parameters and fuzzy approach was applied to identify the safety level of the fireworks factories. The findings could be used by the incharges in the factories to strengthen the safety of the fireworks factories and thereby the lives of the innocent workers could be saved. Future work would be taken to get more accurate findings by applying all possible factors for explosion.

\section{REFERENCES}

[1] http://whatis.techtarget.com/definition/fuzzy-logic

[2] https://en.wikipedia.org/wiki/Fuzzy_set

[3] http://www.doc.ic.ac.uk/ nd/surprise_96/journal/vol 2/jp6/article2.html 
[4] https://www.researchgate.net/publication/22245610 4_Zadeh_LA_The_concept_of_a_linguistic_variabl e_and_its_application_to_approximate_reasoning_P art_1_Inform_Sci_8_199-

249_Part_2_Inform_Sci_8_301-

353_Part_3_Inform_Sci_9_43-80

[5] virtual.cvut.cz/course/syscontrol/node122.html

[6] http://nptel.ac.in/courses/Webcourse-contents/IIT Kharagpur/Artificial intelligence/pdf/Lesson32.pdf

[7] www.indianeagle.com/travelbeats/sivakasi-thefireworks-hub-of-india/

[8] http://www.newindianexpress.com/states/tamil_nad u/article601806.ece
[9] http://www.thehindu.com/news/national/tamilnadu/38-killed-in-sivakasi-cracker-unitblast/article3862000.ece

[10] www2.imse-cnm.csic.es/Xfuzzy/

[11] dipp.nic.in/English/acts_rules/Acts/ExplosivesRules _2008.pdf

[12] https://www.scribd.com/doc/45462115/LicenceForm-Le1

[13] grs.dlmu.edu.cn/batch.download.php 